\title{
Menopause and hormone therapy in the 21 st century: why promote transdermal estradiol and progesterone?
}

\author{
${ }^{1}$ Center for Research in Epidemiology and Population \\ Health, INSERM, Villejuif, France \\ ${ }^{2}$ Paris-Saclay University, Paris-South University, UVSQ, \\ Paris-Saclay, Île-de-France, France \\ ${ }^{3}$ Unité de Gynécologie Endocrinienne, Université de \\ Paris, Paris, France \\ ${ }^{4}$ EA 7449 REPERES (Pharmacoepidemiology and Health \\ Services Research), Université de Rennes, Rennes, \\ France
}

Pierre-Yves Scarabin $\quad{ }^{1}$ Marianne Canonico, ${ }^{1,2}$ Geneviève Plu-Bureau, ${ }^{3}$ emmanuel oger ${ }^{4}$

\author{
Correspondence to Professor Pierre-Yves Scarabin \\ Center for Research in Epidemiology and Population \\ Health, INSERM, Villejuif 69372, France; \\ pierre-yves.scarabin@inserm.fr
}

In their editorial, ${ }^{1}$ Gersh and Lavie describe the many ways that estradiol impacts cardiovascular health. In addition, the authors rightly question the findings of the Women's Health Initiative among meno-pausal women using hormone therapy. Importantly, they emphasise the need for using the most physiological human- identical transdermal estradiol combined with natural progesterone. However, no information is given on both the biolog-ical rationale and the expected benefits of transdermal oestrogens compared with oral oestrogens. Oral but not trans-dermal oestrogens result in a hepatic first- pass effect that may induce reversible prothrombotic changes in haemostatic variables, ${ }^{2}$ including resistance to acti-vated protein C (figure 1). Thrombotic

process plays a critical role in the develop-ment of both venous and arterial diseases. European studies have clearly shown the advantage of transdermal oestrogens with respect to the risk of venous thrombo-embolism ${ }^{3}$ and probably also stroke. The type of progestogens has also emerged as an important determinant of thrombosis. Progesterone has no effect on blood coag-ulation, ${ }^{2}$ and it is the safest progestogen with respect to thrombosis. ${ }^{4}$ Since throm-bosis is one main serious adverse effect of hormone therapy, women should be encouraged to use transdermal oestrogens combined with progesterone.

\section{REFERENCES}

1 Gersh FL, Lavie CJ. Menopause and hormone replacement therapy in the 21 st century. Heart 2020;106:479-81.

2 Scarabin PY, Alhenc-Gelas M, Plu-Bureau G, et al. Effects of oral and transdermal estrogen/progesterone regimens on blood coagulation and fibrinolysis in postmenopausal women. A randomized controlled trial. Arterioscler Thromb Vasc Biol 1997;17:3071-8

3 Scarabin P-Y, Oger E, Plu-Bureau G, et al. Differential association of oral and transdermal oestrogenreplacement therapy with venous thromboembolism risk. Lancet 2003;362:428-32.

4 Scarabin P-Y. Progestogens and venous thromboembolism in menopausal women: an updated oral versus transdermal estrogen meta-analysis. Climacteric 2018;21:341-5.
Provenance and peer review Not commissioned; internally peer reviewed.

Patient consent for publication Not required.

Patient and public involvement Patients and/or the public were not involved in the design, conduct, reporting or dissemination plans of this research.

Funding The authors have not declared a specific grant for this research from any funding agency in the public, commercial or not-for-profit sectors.

Competing interests None declared.

\section{VTE Stroke}

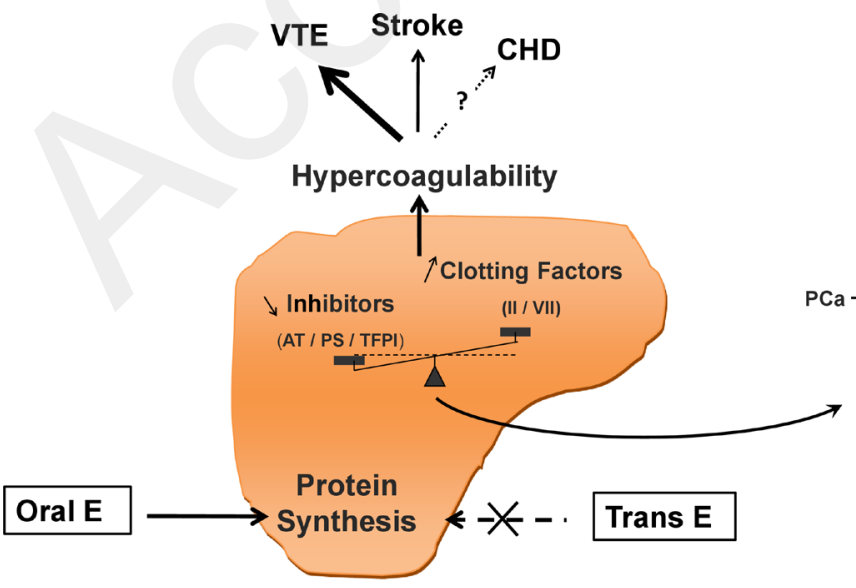

CHD

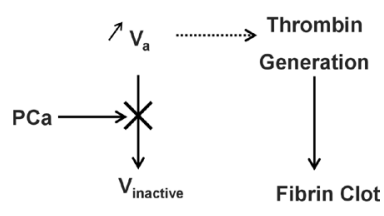

Hepatic First Pass

Figure 1 Caption. 